\title{
Power Flow Control of a Dual-Input Interleaved Buck/Boost Converter with Galvanic Isolation for Renewable Energy Systems
}

Mira Albert, Maria del Carmen; Zhang, Zhe; Knott, Arnold; Andersen, Michael A. E.

\section{Published in:}

Proceedings of APEC 2015

Link to article, DOI:

10.1109/apec.2015.7104780

Publication date:

2015

Document Version

Peer reviewed version

Link back to DTU Orbit

Citation (APA):

Mira Albert, M. D. C., Zhang, Z., Knott, A., \& Andersen, M. A. E. (2015). Power Flow Control of a Dual-Input Interleaved Buck/Boost Converter with Galvanic Isolation for Renewable Energy Systems. In Proceedings of APEC 2015 (pp. 3007-3012). IEEE. https://doi.org/10.1109/apec.2015.7104780

\section{General rights}

Copyright and moral rights for the publications made accessible in the public portal are retained by the authors and/or other copyright owners and it is a condition of accessing publications that users recognise and abide by the legal requirements associated with these rights.

- Users may download and print one copy of any publication from the public portal for the purpose of private study or research.

- You may not further distribute the material or use it for any profit-making activity or commercial gain

- You may freely distribute the URL identifying the publication in the public portal 


\title{
Power Flow Control of a Dual-Input Interleaved Buck/Boost Converter with Galvanic Isolation for Renewable Energy Systems
}

\author{
Maria C. Mira, Zhe Zhang, Arnold Knott, Michael A. E. Andersen \\ Dept. Electrical Engineering \\ Technical University of Denmark \\ Oersteds Plads, 349. Kongens Lyngby, Denmark \\ mmial@elektro.dtu.dk_zz@elektro.dtu.dk_akn@elektro.dtu.dk ma@elektro.dtu.dk
}

\begin{abstract}
DC microgrids or nanogrids have attracted increasing research interest in recent years. Therefore, as a critical component, dc-dc converters with multiple inputs are required. In this paper, a dual-input interleaved buck/boost converter is proposed and its corresponding power flow control methods are analyzed and designed accordingly. Furthermore, the design guidelines are discussed. Finally, in order to verify the validity of this study, the measurement results are presented.
\end{abstract}

Keywords-Dual-input; isolated; interleaved buck/boost; renewable energy systems; energy storage; power flow control.

\section{INTRODUCTION}

Renewable energy sources have become an important part of energy production. The application of clean and renewable energy sources, such as wind energy, solar energy and hydrogen, in de microgrids or nanogrids has been a focus in academia and industry [1], [2], [3]. However, due to intermittent feature of wind and solar sources, wind power and photovoltaic (PV) systems need energy storage units to balance electricity generation and consumption within a power system, which has a high wind/solar energy penetration. In order to fulfill various system requirements, many hybrid system configurations and converter topologies have been proposed and investigated as reviewed in [4]. In order to combine several input power sources two approaches are usually adopted: multiple-converter systems and multiple-port systems. On the one hand, multiple-converter systems are formed by connecting the input sources by individual dc-dc converters. This system configuration offers some advantages such as easier implementation of the power management and control scheme. However, it presents the disadvantage of higher number of components and, consequently, low power density and high cost. On the other hand, multiple-port or multiple-input converters (MIC) [5], [6], [7] have recently been introduced and have attracted increased research interest. In these topologies, the common characteristic is the shared output stage by the different input ports, reducing the cost by reducing the number of components, and increasing the system efficiency and power density. However, the control and power management system tend to become more complex. Some of the proposed MIC do not allow bidirectional operation [8], [9], as the input ports are completely decoupled, and therefore they cannot be used in systems requiring of energy storage units.
Systems interconnecting a renewable energy source and an energy storage unit are usually known as dual-input converters or three-port converters (TPC) [10], [11]. In such a system, the mismatch power is handled by the energy storage unit, which will absorb the surplus energy at light load and will supply the energy deficit at heavy load conditions. Therefore, different power flows can take place depending on the power of the renewable energy source and load consumption.

Based on the previous research [12], in this paper, a dualinput interleaved buck/boost converter with galvanic isolation is proposed. The schematic of the circuit topology is presented in Fig. 1. The proposed converter consists of two interleaved bidirectional buck/boost converters, one transformer, an ac inductor and one full-bridge diode rectifier. Switches $S_{1}$ and $S_{2}$, as well as $S_{3}$ and $S_{4}$, have complementary gate signals with a deadband. The ac inductor, $L_{\mathrm{ac}}$, is the power interface element between the two inputs and the output port. In order to decouple the two power inputs as well as to effectively regulate the output voltage, a duty cycle plus phase-shift control strategy [13], [14] is adopted. The duty cycle of the primary side switches is used to control the power flow between the two independent sources, i.e. $V_{\text {in1 }}$ and $V_{\text {in2. The }}$ phase-shift angle between the middle points of the interleaved half-bridges is employed to regulate the output voltage accordingly. Compared to the topologies investigated in [13] and [15], for the proposed converter, due to the absence of output inductors, there is neither freewheeling current nor reactive power transferring back and forth to the power input. Therefore, higher conversion efficiency than other investigated solutions can be expected.

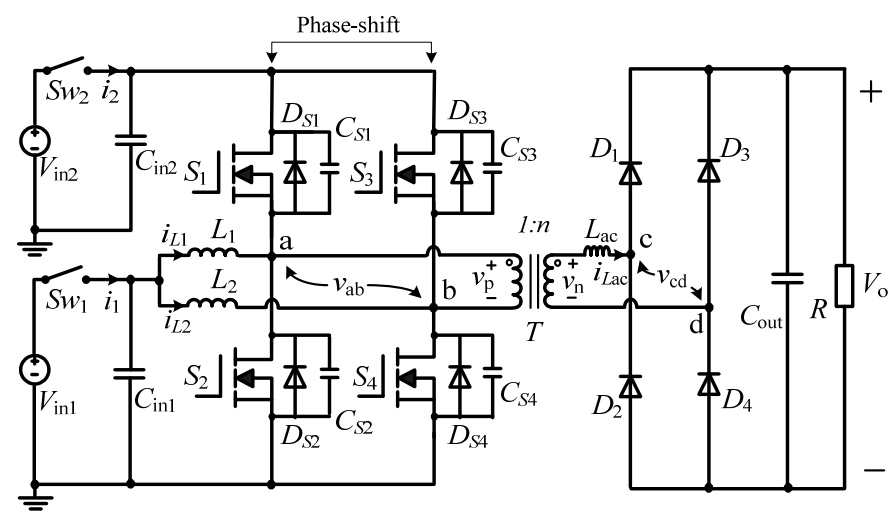

Fig 1. Topology of the interleaved Buck/Boost converter. 


\section{POWER Flow Regulation AND CONTROL}

Different power flows can occur subject to the input power and load consumption. The converter will operate in dual input (DI) mode when the load power is higher than the available input power, so the battery has to deliver the extra required energy. The converter will operate in dual output (DO) mode when the input power is higher than the load power and the battery has to store the excess energy. The system can also operate in single input single output (SISO) mode, when power transfers between the inputs or from one of the inputs to the output port. According to the control variable and the direction of the power flow, the proposed converter can operate in different modes as explained below.

\section{A. Duty cycle control mode}

Power transfers only between the two inputs $V_{\mathrm{in} 1}$ and $V_{\mathrm{in} 2}$, and there is no power delivered to the output. The duty cycle, $D$, is the control parameter while the phase-shift angle $\varphi$ is kept at $\pi$. In this mode, the voltage relationship of $V_{\text {in } 1}$ and $V_{\text {in2 }}$ can be expressed accordingly,

$$
V_{\text {in } 2}=\frac{V_{\text {in } 1}}{(1-D)}
$$

where $D$ is the duty cycle of the low side switches $S_{2}$ and $S_{4}$.

\section{B. Phase-shift control mode}

One input is completely powered off and only the other input supplies power to the load. Based upon the typical operating waveforms, which are depicted in Fig. 2, the output power in this mode can be calculated as,

$$
P_{o}=\frac{2 \cdot\left(2 V_{i n 1}-V_{o}\right) \cdot V_{i n 1}}{f_{s} \cdot L_{a c}} \cdot\left(\frac{\varphi}{2 \pi}\right)^{2} \quad(0<\varphi<\pi)
$$

where $\varphi$ is the phase-shift angle of $S_{2}$ and $S_{4}$.

\section{Duty cycle plus phase-shift control mode}

Switches $S_{w 1}$ and $S_{w 2}$ are turned on and both of the inputs can deliver power to the load. In order to decouple the two inputs effectively as well as regulate the output voltage accurately, both the duty cycle and the phase-shift angle are used as the control variable. Therefore, the power flowing between the inputs and the power delivered to the load are controlled by $D$ and $\varphi$, respectively.

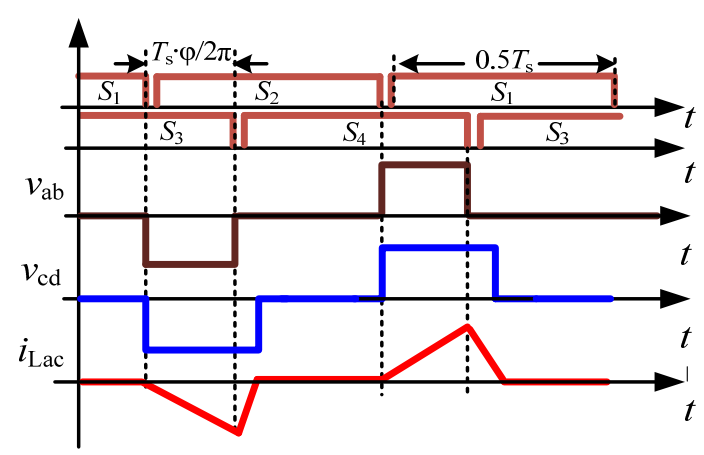

Fig. 2. Operating waveforms in phase-shift control mode.
The typical operating waveforms are shown in Fig. 3 where $\varphi / 2 \pi<\min [D,(1-D)]$. The equivalent circuits in each time interval are presented in Fig. 4. During the first subinterval, shown in Fig. 4 (a), switches $S_{2}$ and $S_{3}$ are conducting and switches $S_{1}$ and $S_{4}$ are off. The upper point of the transformer, $V_{\mathrm{a}}$, is zero and the voltage applied to the transformer primary side is negative and determined by the input voltage source $V_{\text {in2 }}$. The inductor current $i_{\text {Lac }}$ flows to the load through diodes $D_{2}$ and $D_{3}$. During time interval $t_{1}$ to $t_{2}$, switch $S_{3}$ turns off and $S_{4}$ turns on, as shown in Fig. 4 (b). The voltage applied to the transformer is clamped at zero and the inductor current discharges through diodes $D_{2}$ and $D_{3}$ to the output. The equivalent circuit during time interval $t_{2}$ to $t_{3}$ is shown in Fig. 4 (c). The voltage on the transformer is still clamped to zero and the energy to the load is supplied by the output capacitor. At time $t_{3}$, switch $S_{2}$ turns off and switch $S_{1}$ turns on. The voltage applied to the transformer is positive and determined by $V_{\text {in2. At }}$ the secondary side, the power is transferred to the load through diodes $D_{1}$ and $D_{4}$. It can be observed that the phase-shift determines the time interval from $0 \sim t_{1}$ and the duty cycle defines the time interval from $0 \sim t_{3}$. The output power can be calculated as shown in (3).

$$
P_{o}= \begin{cases}\frac{m(m-1) V_{o}^{2}}{L_{a c} f_{s}} \cdot\left(\frac{\varphi}{2 \pi}\right)^{2}, & \frac{\varphi}{2 \pi} \leq \min [D, 1-D] \\ \frac{m(m-1) V_{o}^{2}}{L_{a c} f_{s}} \cdot D^{2}, & D<\frac{\varphi}{2 \pi}<0.5 \\ \frac{m(m-1) V_{o}^{2}}{L_{a c} f_{s}} \cdot(1-D)^{2}, & 1-D<\frac{\varphi}{2 \pi}<0.5 \\ m=\frac{n V_{a b}}{V_{c d}}=\frac{n V_{i n 1}}{(1-D) V_{o}}=\frac{n V_{i n 2}}{V_{o}}\end{cases}
$$

From (3), it can be noticed that the phase-shift angle can only regulate the output power if the condition shown in (5) is satisfied.

$$
\frac{\varphi}{2 \pi}>1-D(D>0.5) \text { and } \frac{\varphi}{2 \pi}>D(D<0.5)
$$

On the other hand, when the converter is supplied with a constant input voltage and connected to a constant resistive load, changing the phase-shift angle will lead to a variable $m$. In this condition, the output voltage varies as a function of phase-shift angle and the duty cycle as shown in Fig.5.

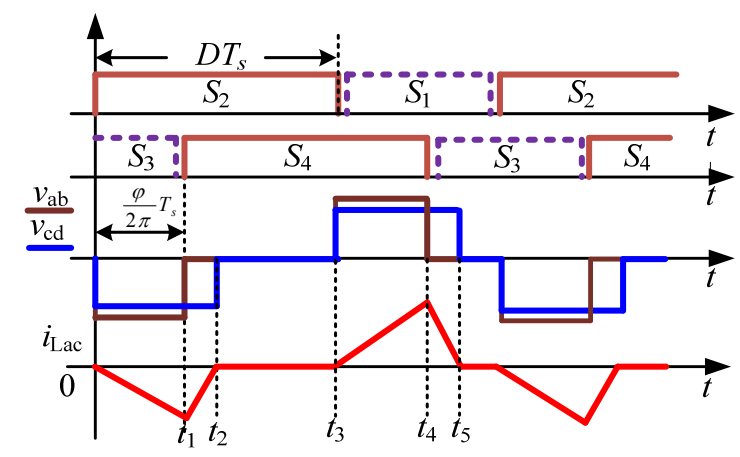

Fig. 3. Operating waveforms in duty cycle plus phase-shift control mode. 


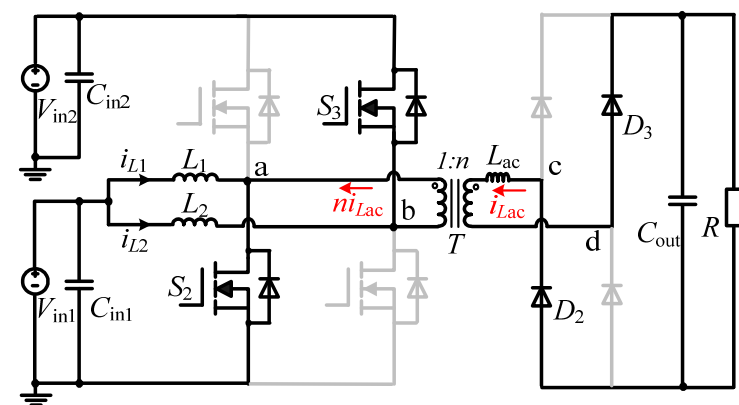

(a)

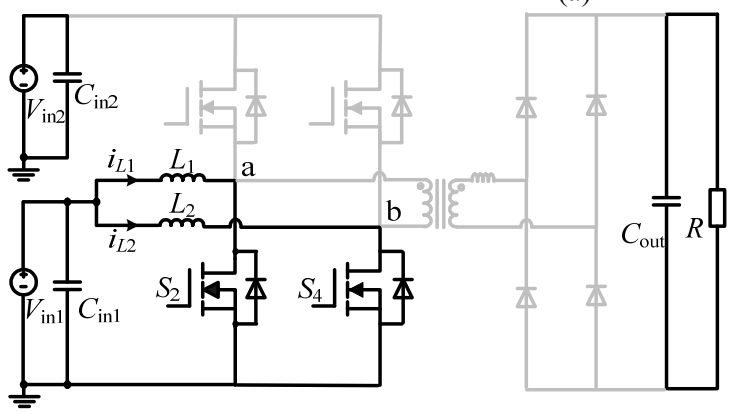

(c)

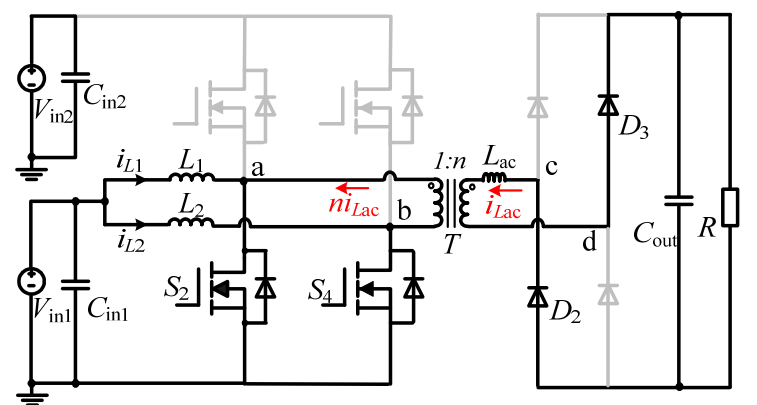

(b)

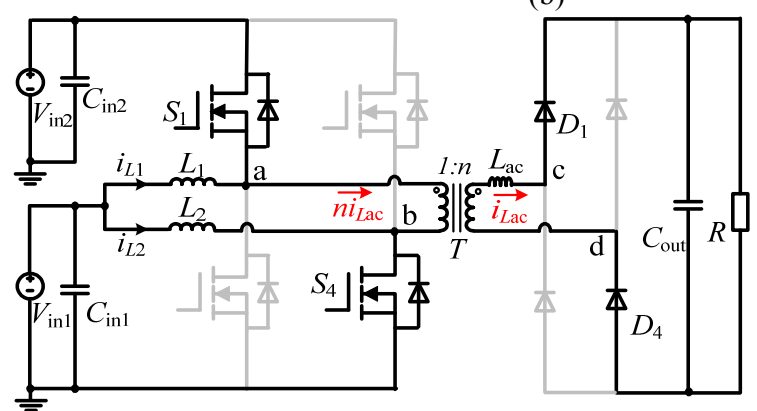

(d)

Fig. 4. Equivalent circuits in duty cycle plus phase-shift control mode. (a) Interval $\left[0 \sim t_{1}\right]$, (b) interval $\left[t_{1} \sim t_{2}\right]$, (c) interval $\left[t_{2} \sim t_{3}\right]$, and (d) interval $\left[t_{3} \sim t_{4}\right]$.

\section{DESIGN GUIDELINES}

\section{A. No-reactive power operation}

In order to achieve the operation without reactive power, which means ac current $i_{\text {Lac }}$ and voltage $v_{\mathrm{cd}}$ are in phase, the inequality below must be satisfied.

$$
\frac{(1-D)^{2} \cdot V_{o}}{n V_{i n 1}}=\frac{(1-D) \cdot V_{o}}{n V_{i n 2}} \geq \frac{\varphi}{2 \pi}
$$

\section{B. Soft-switching constraints}

To ensure operation of zero voltage switching (ZVS) at turn on, current flowing through MOSFETs $S_{1} \sim S_{4}$ must be negative when the corresponding MOSFET is triggered. Therefore, the voltage across the MOSFET is clamped by the forward biased voltage of its body diode. As the waveforms shown in Fig. 3, where $\varphi / 2 \pi<(1-D)$ and $D>0.5$, when the input $V_{\text {in1 }}$ provides power to the load, the MOSFET $S_{2}$ in the leading half-bridge cannot operate under ZVS. However, MOSFET $S_{4}$ in the lagging half-bridge can achieve ZVS if the constraints depicted in Fig. 6 are satisfied. Due to the operation principle of buck/boost converters, the high side switches $S_{1}$ and $S_{3}$ can operate under ZVS inherently.

\section{Current stress over switches}

Due to the absence of output inductors, the MOSFETs always switch off the current at its peak. Consequently, the current stress is relatively high, which leads to high switching losses. On the other hand, when $V_{\text {in } 1}$ provides power to the load, the current stress has imbalanced distribution among the power MOSFETs.

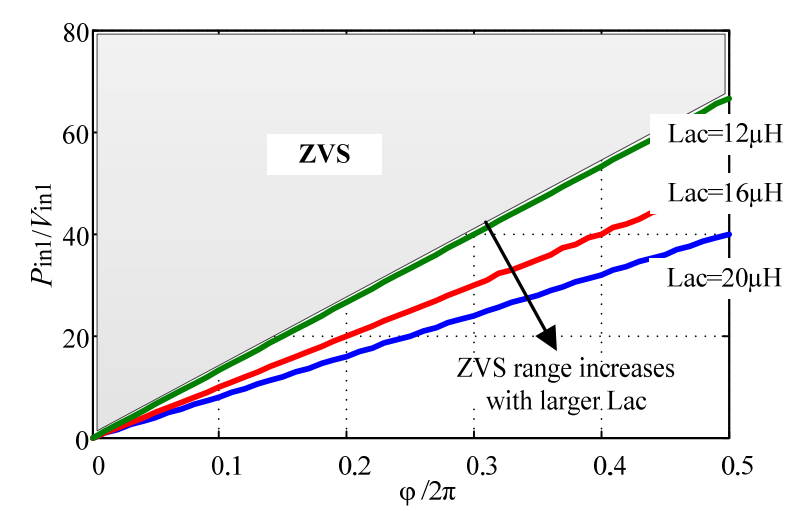

Fig 6. ZVS range with $V_{\text {in } 2}=100 \mathrm{~V}$ and $V_{\mathrm{o}}=380 \mathrm{~V}$.

Fig. 5: Output voltage as a function of phase-shift angle with different $m$ and $D$. 


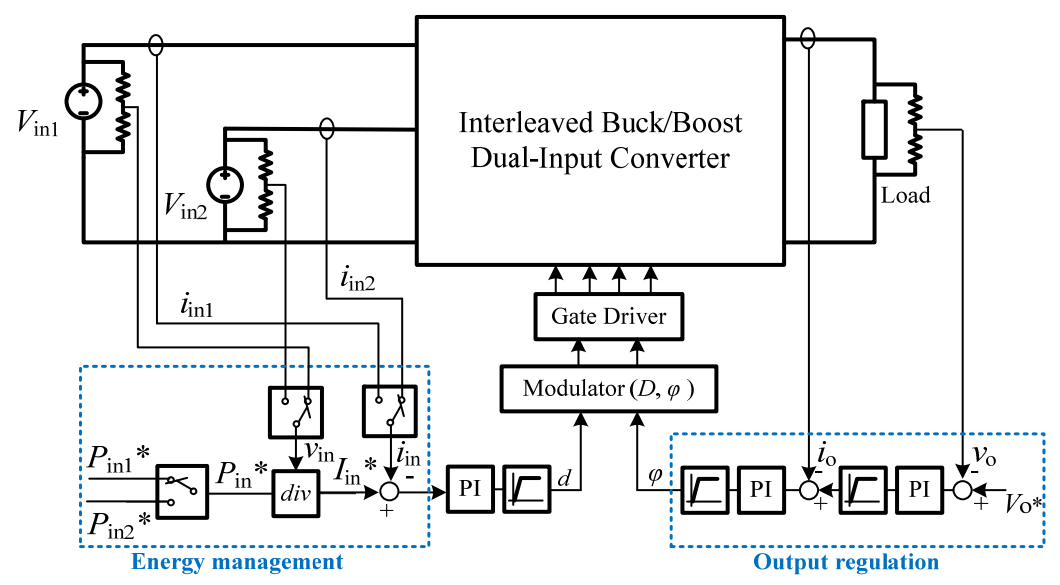

Fig 7. Block diagram of energy/power management and control.

\section{Energy / power management and control}

In order to control the power among the two inputs and the load, the block diagram of the designed power management and feedback controller is shown in Fig. 7. The output regulation loop is employed to regulate the load voltage by the phase-shift angle $\varphi$. Assuming $V_{\text {in } 1}$ is the renewable energy source such as fuel cell or photovoltaic, its power is controlled by the duty cycle $D$. The power from the other input $V_{\text {in2 }}$ as an energy storage unit, for example a battery or a super capacitor bank, can be controlled dependently. The energy management and control scheme can be summarized in the following way. On the one hand, if both of the input sources are available, the multi-terminal switches are set to control the input power of the renewable source, i.e. by a maximum power point tracking (MPPT) algorithm, and the storage unit will compensate for the power difference automatically. On the other hand, if the renewable energy source is not available, i.e. during night time in the case of solar energy, the multi-terminal switches are set to control the power of the energy storage unit. Finally, the state of charge (SOC) of the energy storage can be regulated as well. If the SOC of the energy storage is below its maximum, the multi-terminal switches are set to $P_{\text {in2 }}, V_{\text {in2 }}$ and $I_{\text {in2 }}$ and the storage unit is charged by $V_{\text {in1 }}$ until it reaches its maximum SOC. At this moment, switch $S_{w 2}$ will be turned off and the load will be supported only by the renewable source $V_{\text {in1 }}$.

\section{EXPERIMENTAL RESULTS}

To verify the theoretical analysis above, an experimental prototype of the dual-input interleaved buck/boost converter has been constructed. The transformer is implemented with planar magnetics as it can be observed from the laboratory prototype shown in Fig. 8. The system specifications and the components used in the prototype are presented in Table 1. MOSFETs $S_{1} \sim S_{4}$ are driven by gate drivers IR2110. The current at the input and output ports are measured with Hall effect current transducers LEM LA55-P, LA25-NP, respectively. The sensed signals are low pass filtered to avoid noise at the inputs of the analog-to-digital converter (A/D). A 32 bit digital signal processor (DSP) TMS320F28035 is used to generate the corresponding PWM gate signals and phase-shift angle. The used control law is an assembly (ASM) function included in the library API for Piccolo B (C2803x). This control law implements a digital controller named 2P2Z optimized for minimal time delay calculation. The $\mathrm{A} / \mathrm{D}$ converter is triggered when the PWM1A counter register is equal to zero, the sampled value is then given to the $2 \mathrm{P} 2 \mathrm{Z}$ controller and the corresponding duty cycle and/or phase-shift values are calculated as a function of the reference, the sampled values and the digital controller parameters.

In order to test bidirectional capability of the input ports, the set-up is configured to simulate the behavior of an energy storage unit, i.e. a super capacitor or battery bank. This is carried out with a power supply parallel-connected with an electronic load configured in constant voltage $(\mathrm{CV})$ mode.

TABLE I

SYSTEM SPECIFICATIONS AND COMPONENTS

\begin{tabular}{cc}
\hline \hline Input voltage & $V_{\text {in1_max }}=60 \mathrm{~V}$ \\
& $V_{\text {in2_max }}=120 \mathrm{~V}$ \\
Maximum output power & $P_{\text {out_max }}=1.5 \mathrm{~kW}$ \\
$S_{1} \sim S_{4}$ & IRFB4115 $(150 \mathrm{~V} / 104 \mathrm{~A})$ \\
$D_{1} \sim D_{4}$ & HFA08TB60 $(600 \mathrm{~V} / 8 \mathrm{~A})$ \\
Transformer $T$ & $4: 16$, ELP64/10/50 Ferrite N87 \\
Inductors $L_{1}$ and $L_{2}$ & $55 \mu \mathrm{H}$ N41 gapped RM12 core \\
Inductor $L_{\mathrm{ac}}$ & $20 \mu \mathrm{H}$ Coilcraft $1228 \mathrm{D}$ \\
Capacitors $C_{\text {in } 1 \text { and } C_{\text {in2 }}}$ & $2 \times 10 \mu \mathrm{F} 160 \mathrm{~V}$ WIMA MKP4 \\
Capacitor $C_{\text {out }}$ & $3 \times 22 \mu \mathrm{F} 63 \mathrm{~V}$ AV MKT \\
Switching frequency & $2 \times 10 \mu \mathrm{F} 700 \mathrm{~V}$ VISHAY MKP \\
Digital controller & $60 \mathrm{kHz}$ \\
\hline \hline
\end{tabular}

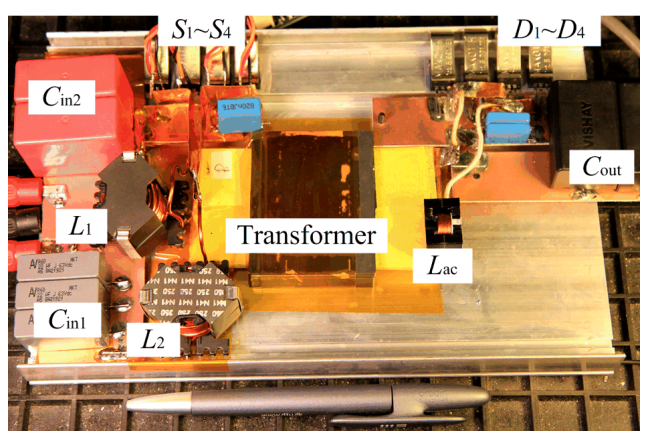

Fig. 8. Experimental laboratory prototype. 
Figure. 9 shows experimental waveforms of the voltages $V_{a b}$ and $\mathrm{V}_{\mathrm{cd}}$ toghether with the ac inductor current. It can be observed that the experimental waveforms can match their theoretical counterparts shown in Fig. 3.

The performance of the implemented energy management system and control loops is verified by different experimental measurements. Fig. 10 to Fig. 15 show the input current of both of the converter input ports, $I_{\text {in } 1}$ and $I_{\text {in2 }}$, in green and blue lines, respectively, as well as the load current, $I_{0}$, in red. Fig. 10 shows a step change in the reference of the input current $I_{\text {in } 1}$ when the converter is operating in SISO mode and it changes to DO mode. At first, the current at the bidirectional port, $I_{\text {in2 }}$, is zero and the load is supplied only by the renewable source $P_{\text {in1 }}$. An increment in the available power makes the energy storage port to start absorbing the energy surplus, while the power at the output remains constant. Fig. 11 shows a step change in the reference of the input current $I_{\text {in1 }}$ when the converter is operating in DI mode. As it can be observed, in this mode both of the inputs are delivering power to the output. If a variation in the available power occurs, the power between the inputs is immediately balanced, while the power at the output remains constant. Fig. 12 and Fig. 13 show a load step when the converter operates in DI mode. If the input power of the renewable source is controlled, i.e. by a maximum power point tracking (MPPT) algorithm, and there is a request of energy by the load, the bidirectional port automatically compensates the load energy demand, while the input current of the renewable source is kept constant. In Fig. 12, at first the converter is working in SISO. When there is an energy demand from the load, the energy storage unit starts delivering power to the load, while the power of the renewable source is kept constant. In Fig. 13, the converter is operating in DI mode, so both of the input sources deliver energy to the output. When the energy demand at the load decreases, the power at the storage unit is compensated automatically and the load is supported only by the renewable source in SISO mode. In the same way, a load step is tested when the converter operates in DO mode. In this case, the renewable energy source is delivering power to both the output and the energy storage unit. When an increment or decrement in the energy required at the output occurs, the energy storage unit balances the energy while keeping the power of the renewable source constant. The results are shown in Fig. 14 and Fig. 15, respectively.

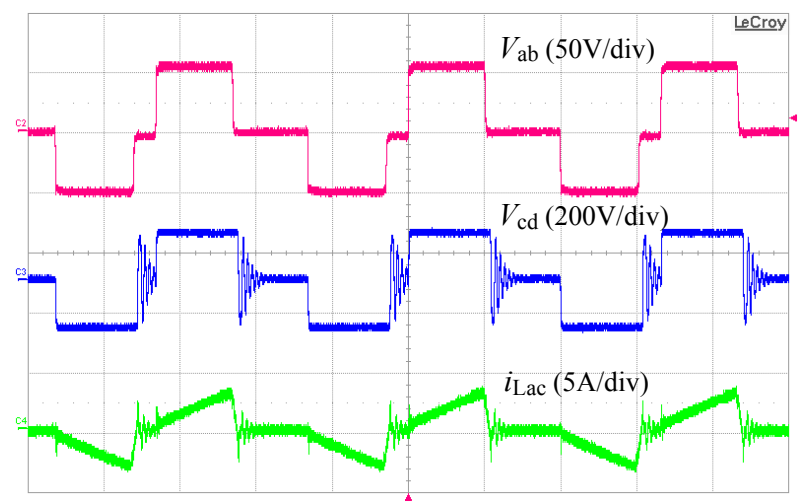

Fig. 9. Experimental waveforms of $V_{\mathrm{ab}}, V_{\mathrm{cd}}$ and $i_{\text {Lac }}$ at duty cycle $D=0.7$ and phase-shift angle $\varphi=0.8 \pi$. Time scale: $5 \mu \mathrm{s} / \mathrm{div}$.

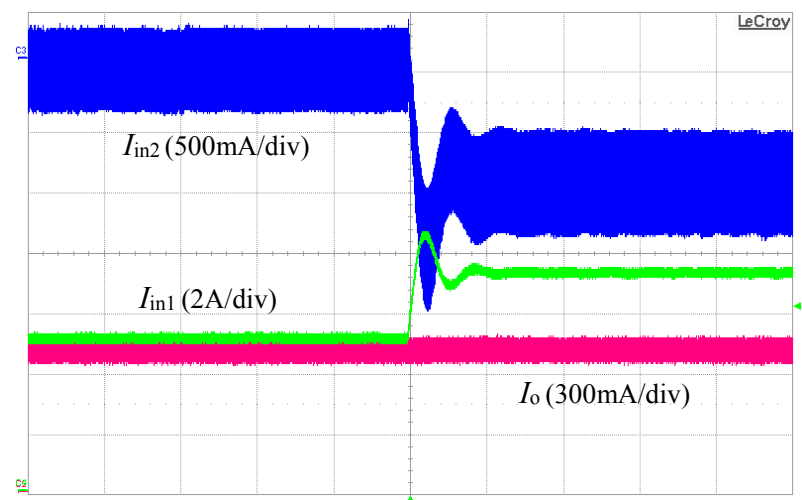

Fig. 10. Step change in the reference of the input current $I_{\text {in1 }}$ during DO mode operation of the converter. Time scale: $1.6 \mathrm{~ms} / \mathrm{div}$.

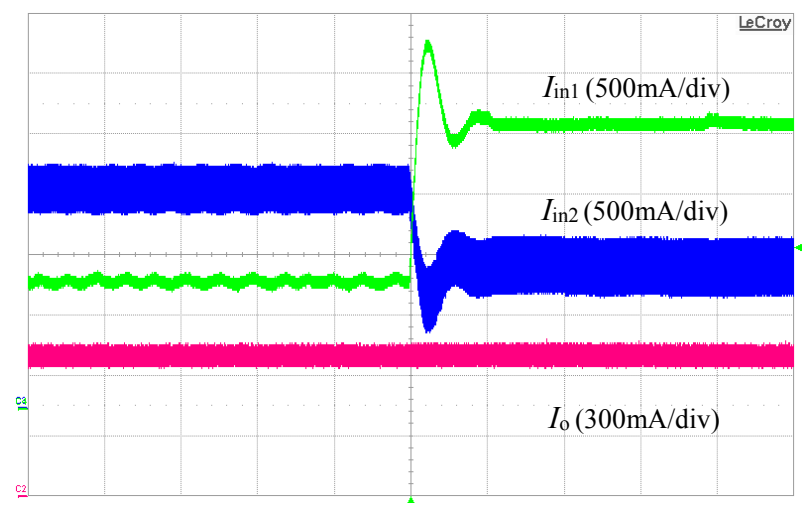

Fig. 11. Step change in the reference of the input current $I_{\text {in } 1}$ during DI mode operation of the converter. Time scale: $1.6 \mathrm{~ms} / \mathrm{div}$.

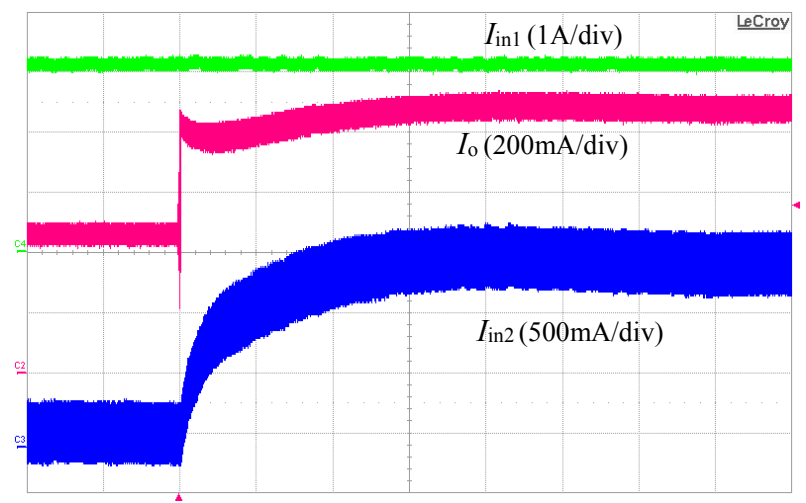

Fig. 12. Load step forcing the converter operation to change from SISO to DI mode. Time scale: $3.2 \mathrm{~ms} / \mathrm{div}$.

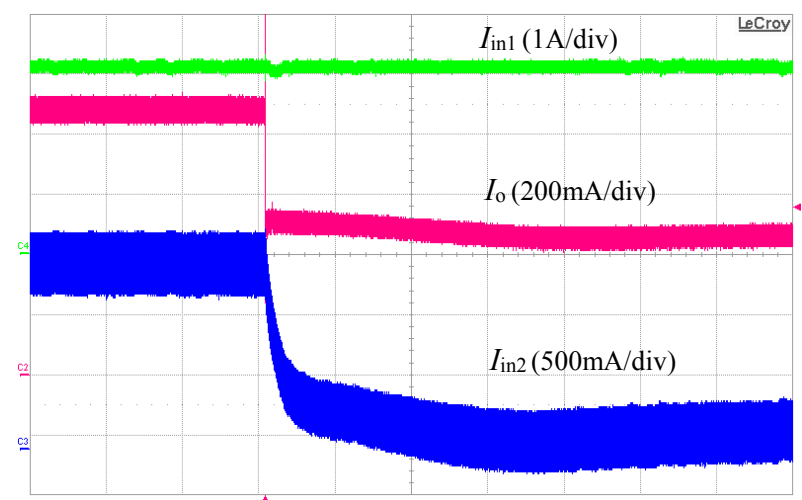

Fig. 13. Load step forcing the converter operation to change from DI mode to SISO. Time scale: $3.2 \mathrm{~ms} /$ div. 


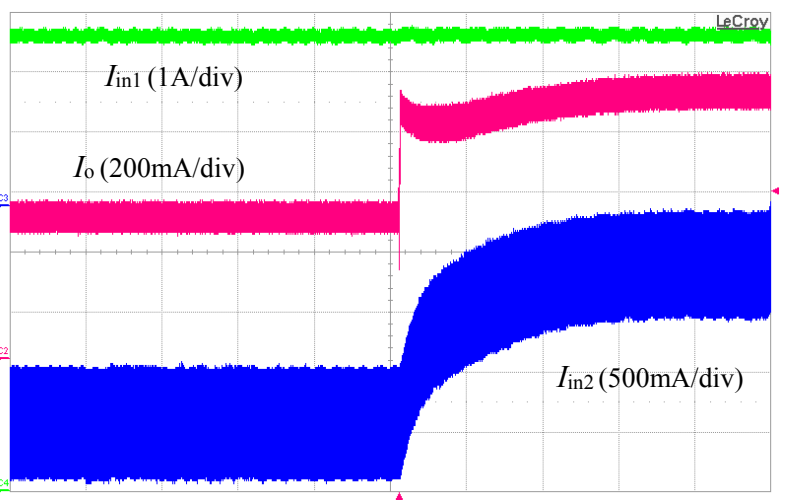

Fig. 14. Load step during DO mode operation of the converter. Time scale: $3.2 \mathrm{~ms} / \mathrm{div}$.

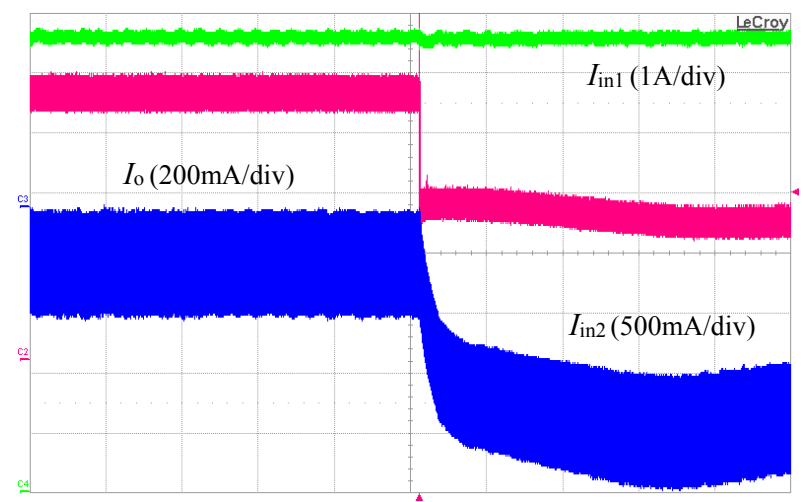

Fig. 15. Load step during DO mode operation of the converter. Time scale: $3.2 \mathrm{~ms} / \mathrm{div}$.

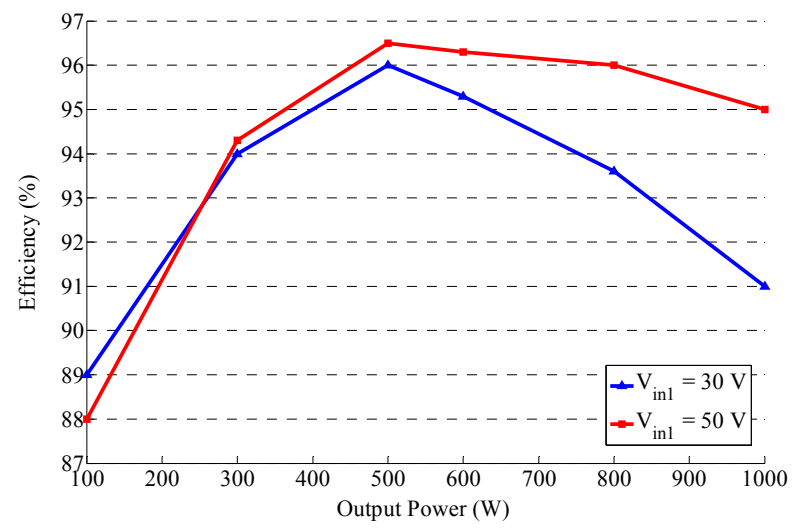

Fig. 16. Laboratoty prototype measured efficiency.

Finally, the measured efficiency curves at input voltage $V_{\text {in1 }}$ of $30 \mathrm{~V}$ and $50 \mathrm{~V}$, respectively are given in Fig. 16. In the worst case scenario (lowest voltage and full power), the converter efficiency reaches over $91 \%$. Compared to other topologies with similar configuration proposed in previous literature, the freewheeling current and ac reactive power are eliminated; therefore, the efficiency is improved.

\section{CONCLUSIONS}

In this paper, a newly proposed dual-input isolated dc-dc converter based on an interleaved buck/boost circuit is analyzed and designed. The converter shows good characteristics to be used in hybrid renewable energy systems, where an energy storage unit is required. In order to control the power flow between the different ports, duty cycle plus phase-shift control scheme is adopted. The duty cycle is used to control the power flow between the two independent sources, while the phaseshift angle is employed to regulate the output voltage. Different experimental results demonstrate that the proposed energy/power management solution achieves total control of the power flow between the input port and output ports.

\section{REFERENCES}

[1] D. Boroyevich, I. Cvetkovic, R. Burgos and D. Dong, "Intergrid: A Future Electronic Energy Network?," IEEE Journal of Emerging and Selected Topics in Power Electronics, vol. 1, no. 3, pp. 127-138, 2013.

[2] X. She, A. Huang, S. Lukic and M. Baran, "On Integration of Solid-State Transformer With Zonal DC Microgrid," IEEE Transactions on Smart Grid, vol. 3, no. 2, pp. 975-985, 2012.

[3] H. Hu, S. Harb, N. Kutkut, I. Batarseh and Z. Shen, "A Review of Power Decoupling Techniques for Microinverters With Three Different Decoupling Capacitor Locations in PV Systems," IEEE Transactions on Power Electronics, vol. 28, no. 6, pp. 2711-2726, 2013.

[4] M. Nehrir, C. Wang, K. Strunz, H. Aki, R. Ramakumar, J. Bing, Z. Miao and Z. Salameh, "A Review of Hybrid Renewable/Alternative Energy Systems for Electric Power Generation: Configurations, Control, and Applications," IEEE Transactions on Sustainable Energy, vol. 2, no. 4, pp. 392-403, 2011.

[5] H. Matsuo, W. Lin, F. Kurokawa, T. Shigemizu and N. Watanabe, "Characteristics of the multiple-input DC-DC converter," IEEE Transactions on Industrial Electronics, vol. 51, no. 3, pp. 625-631, 2004.

[6] Y. Li, X. Ruan, D. Yang, F. Liu and C. Tse, "Synthesis of Multiple-Input DC/DC Converters," IEEE Transactions on Power Electronics, vol. 25, no. 9, pp. 2372-2385, 2010.

[7] H. Tao, A. Kotsopoulos, J. Duarte and M. Hendrix, "Family of multiport bidirectional DC-DC converters," IET Journals \& Magazines - IEE Proceedings Electric Power Applications, vol. 153, no. 3, pp. 451-458, 2006.

[8] Z. Ouyang, Z. Zhang, M. Andersen and O. Thomsen, "Four Quadrants Integrated Transformers for Dual Input Isolated dc dc converters," IEEE Transactions on Power Electronics, vol. 27, no. 6, pp. 2697-2702, 2012.

[9] Y.-M. Chen, Y.-C. Liu and F.-Y. Wu, "Multi-input DC/DC converter based on the multiwinding transformer for renewable energy applications," IEEE Transactions on Industry Applications, vol. 38, no. 4, pp. 1096-1104, 2002.

[10] H. Wu, K. Sun, R. Chen, H. Hu and Y. Xing, "Full-Bridge Three-Port Converters With Wide Input Voltage Range for Renewable Power Systems," IEEE Transactions on Power Electronics, vol. 27, no. 9, pp. 3965-3974, 2012.

[11] H. Krishnaswami and N. Mohan, "Three-Port Series-Resonant DC-DC Converter to Interface Renewable Energy Sources With Bidirectional Load and Energy Storage Ports," IEEE Transactions on Power Electronics, vol. 24, no. 10, pp. 2289-2297, 2009.

[12] Z. Zhang and M. Andersen, "Interleaved Boost-Half-Bridge Dual-Input DC-DC Converter with a PWM Plus Phase-Shift Control for Fuel Cell Applications," in 39th Annual Conference of the IEEE Industrial Electronics Society, IECON 2013, 2013.

[13] W. Li, J. Xiao, Y. Zhao and X. He, "PWM Plus Phase Angle Shift (PPAS) Control Scheme for Combined Multiport DC/DC Converters," IEEE Transactions on Power Electronics, vol. 27, no. 3, pp. 1479-1489, 2012.

[14] Z. Zhang, O. Thomsen and M. Andersen, "Soft-Switched Dual-Input DC-DC Converter Combining a Boost-Half-Bridge Cell and a VoltageFed Full-Bridge Cell," IEEE Transactions on Power Electronics, vol. 28, no. 11, pp. 4897-4902, 2013.

[15] H. Wu, P. Xu, H. Hu, Z. Zhou and Y. Xing, "Multiport Converters Based on Integration of Full-Bridge and Bidirectional DC-DC Topologies for Renewable Generation Systems," IEEE Transactions on Industrial Electronics, vol. 61, no. 2, pp. 856-869, 2014. 